\title{
Spirituality and Self-Actualization
}

\author{
MELINDA C. PAUSANOS
}

\begin{abstract}
Spirituality is considered as an important factor in the development of self-actualization among older adults as stated in the Theory on Attaining SelfActualization among Older Adults. This study validated this assumption of the theory. This descriptive-correlational study utilized a multi-stage sample of 180 senior citizens in Tagbilaran City, Bohol. A 3-part instrument package was utilized to (1) describe the respondents' demographic profile and obtain measures for their (2) spirituality using the 12-item Functional Assessment of Chronic Illness Therapy-Spiritual Well-Being Scale (FACIT-Sp) and (3) self-actualization using a 16-item questionnaire developed by Boyum (2004). A Somer's $d$ analysis indicated that spirituality of the older adult is significantly correlated with selfactualization $(p=.019)$. This study revealed that older adults with a strong sense of spirituality tend to be more self-actualized.
\end{abstract}

\section{KEYWORDS}

Older adult, spirituality, self-actualization, Filipino family, Tagbilaran City, Philippines 


\section{INTRODUCTION}

How do older adults manage to accept declines and losses yet still feel whole and complete and anticipate death with calm composure? One possibility, consistent with Peck's and Erikson's emphasis on a transcendent perspective among the elderly, is the development of a more mature sense of spirituality. In the Theory of Attaining Self-actualization among Older Adults, it is stated that a person's sense of spirituality is an important characteristic which will help him attain self-actualization in older life. Hence, this study focused on validating this assumption of the theory.

Spirituality is a belief in a power operating in the universe that is greater than oneself, a sense of interconnectedness with all living creatures, and an awareness of the purpose and meaning of life and the development of personal, absolute values (Zinnbauer, Pargament, \& Scott, 1999). This idea purports that spirituality enables one to find meaning, hope, comfort, and inner peace in life. Spirituality is in confluence with self-actualization. Sense of fulfillment should be tempered with spirituality because without it, a person would fall prey to his/her selfish motives. Afterall, the Bibles warns, "what does it matter if a man owns the whole world but loses his soul" (Luke, 12:31). Self-actualization will only be in good shape if this is pursued without losing sight of one's spirituality and in the conflict of common good.

Although spirituality is often associated with religious life, many believe that personal spirituality can be developed outside of religion. Acts of compassion and selflessness, altruism, and the experience of inner peace are all characteristics of spirituality (Fitchett \& Canada, 2012).

Spirituality and religion are important constructs in the lives of many older adults (Taylor, Chatters, \& Jackson, 2007). One of the studies manifested that, among those 65 and older, $72 \%$ report that religion is very important in their lives. This represents the highest percentage reported by any of the age groups surveyed by the Gallup organization (Newport, 2006). Over half of U.S. elders attend religious services or other events weekly; nearly two-thirds watch religious TV programs; and about one-fourth pray at least three times a day (Princeton Religion Research Center, 1999; as cited in Berk, 2010).

Basing from the literature reviewed, it was found out that some older adults, due to their age, experience attainment of spiritual domain. Consequently, spirituality is a predictor of self-actualization. Spirituality exists wherever a person will struggle with the issues of how lives fit into the greater scheme of 
things. A person also becomes spiritual when he/she is moved by values such as beauty, love, or creativity that seem to reveal a meaning or power beyond the visible world.

In the case of Filipino older adults, they are known for their strong religiosity. Dependence on the benevolence of a Transcendent Being is a deeply held value and belief among Filipinos. While this has sometimes produced a certain degree of fatalism, Filipino religiosity provides a moral anchor to individuals when confronted with a personal crisis. Religiosity is the beacon of light as an individual grapples with difficult decisions and struggles to follow the dictate of his superego (Cruz, 2004).

"Nasa Diyos ang awa, nasa tao ang gawa (It is God's prerogative to show compassion while it is man's to act)," underscores their deep sense of the limits of human effort, even as the necessity of hard work is also recognized. Moral righteousness is often equated with being God-fearing. A person described as possessing fear of God ("takot sa Diyos") is considered trustworthy (Cruz, 2004).

These postulations are similar to those of Newport (2006) who contend that people with high spiritual commitment were twice as likely to say that they were "very happy" compared to those with low spiritual commitment. Studies have also examined whether different types of spiritual experiences have an impact on a person's ability to self actualize (Larsen \& Buss, 2008). Definition of religious experience types (confirming, responsive, ecstatic, and revelation) found no differences between type of religious experience and self-actualization. In the study, the difference in level of subjective well-being and personal growth (selfactualization) were based on the type of religious experience a person has. There is a great general variability in the way in which he/she categorizes religious and spiritual experiences (Seligman, 2002).

However, the idea concerns only in the incidence and centrality of a person's self-defined spiritual experience. An older person, who considers his or her spiritual experience to be a central part of his or her life, has higher scores on self-actualization (Larsen \& Buss, 2008).

Molinatti (2012) conducted a study that examined the meaning and the importance of spirituality in the well elderly who reside in their own home and the significant spiritual experiences that they encounter through relationships, religion, and services. Results revealed that regardless of a person's family history, educational background, or religious upbringing, spirituality played a certain role in their daily lives and that there is a powerful influential spiritual force that guides them during periods when they may be lonely or suffering from 
a feeling of being isolated from the outside world. Each of the participants felt that they had knowledge of the various modalities and how spirituality plays a principal role in a spectrum of real-life practices including prayer, helping others, or just staying attune with the beauty of the world around them.

The flow experience is associated with internalizing spirituality as a form of intrinsic motivation (Dehler \& Welsh, 1994). Other authors identify spirituality as a continuous development process that emphasizes meditation, introspection and therapy (Ebersole, 2005).

Consequently, spirituality is assumed as a process of development of the self towards higher consciousness and adult self-actualization. Sequential stepping stones in the development of spirituality include living life according to what the person perceives as ultimately important and meaningful. This concept points that spirituality is an act of compassion and selflessness and the experience of inner peace.

However, the spirituality of an older adult considers the wholeness of being connected to something greater than the individual. Spirituality can be, and should be, a large part of the religious experience. Spirituality refers to one's selfexploration, in forms of meditation, prayer and contemplation. These practices allow a person to be in accord with the essence of their being. These could also be a way of looking out into nature or the world and feeling of connection with nature or an individual's metaphorical understanding of the universe (Hodge, Bonifas, \& Chou, 2010).

In the case of Filipinos they are known for their strong religiosity for which the most striking feature of self-actualization and spirituality is their openness to experience and interaction. It is thought that older adults who have a sense of spirituality demonstrate behaviors that protect and develop health more easily.

Older adults are sometimes egocentric (self-centered) which occurs when they claim more responsibility for themselves and credit for positive outcomes. This might simply be self-serving bias. Older adults exhibit egocentric bias that cite them as overly responsible for negative outcomes; thus, becoming spiritual in nature. Being spiritual does not mean being perfect. A healthy spiritual older adult person is fully aware of his/her human limitations (Bredle, Salsman, Debb, Arnold, \& Cella, 2011).

The perspective is true in which Filipino older adults maintain that in the stage of crisis, they will remain still and peaceful. The Filipino older adult reflects and prays, looks inward or upward to the Almighty for answers to his/her struggle, and surrenders rather than trying to control the situation intellectually 
(searching desperately for answers he doesn't have). Letting go and letting God do the work brings this individual more security than trying harder to do more. Spirituality of an older adult exists whenever they struggle with the issues of how lives fit into the greater scheme of things. They also become spiritual when they become moved by values such as beauty, love, or creativity that seems to reveal a meaning or power beyond the visible world. In view of these, spirituality can refer to an ultimate or an alleged immaterial reality; an inner path enabling a person to discover the essence of his/her being; or the "deepest values and meanings by which people live (Koltko-Rivera, 2006).

Moreover, the importance of spirituality among older persons is in their quality of life, especially for helping them live with the losses and limitations as well as the possibilities of their own particular situations. Spirituality is important in the lives of older adults as they seek to identify, trust, and invest in meanings, values, and relationships that cannot be lost or taken away by the unexpected changes of the aging process; cope with anxieties associated with the losses and limitations and the threats of loss and limitation associated with aging; accept, grieve, cope with, and transcend particular experiences of loss and limitation; recognize, affirm, and actualize realistic possibilities in their situations in spite of losses and limitations; accept, cope with, and transcend pain and suffering; and accept, cope with, and transcend the realities of death and dying (Petrides, 2009).

This study aimed to validate the assumption of the Theory on Attaining SelfActualization among Older Adults by determining whether spirituality and selfactualization significantly correlate with each other. This study hypothesized that persons with a strong sense of spirituality are those who are self-actualized; hence, the better the spirituality of a person, the higher is the level of selfactualization.

\section{METHODOLOGY}

To meet the study objectives, the researcher made use of a descriptivecorrelational design to test the hypothesis that the level of self-actualization of older adults is influenced by their level of spirituality.

Employing a multistage sampling technique, 180 older adults from eight selected barangays in Tagbilaran City, Bohol, participated in the study. Those ages 60 to 75 years old were eligible to participate. The only criteria for exclusion would be the presence of significant cognitive and neurosensory deficits. 
Through several home visits conducted by the researcher and her trained research assistants, respondents were personally invited to participate in the study. Prior to data-gathering, informed consent was sought which involved a thorough verbal and written explanation of the study objectives and allowing time for questions or concerns to be entertained. It was likewise emphasized to the older adults that joining the study is entirely voluntary. They may refuse to answer the questionnaire as they wish and non-participation in the study would not affect them in any way.

Self-report measures were utilized to yield data on the study variables. A three (3) - part research instrument, accomplishable in 30 to 45 minutes, was put together for this purpose. The first part is a researcher-made questionnaire which obtained the demographic profile of each respondent. The second and third parts are standardized instruments namely the Functional Assessment of Chronic IIlness Therapy-Spiritual Well-Being Scale (FACIT-Sp) and Boyum's Self-Actualization Scale, which measured spirituality and self-actualization, respectively. To facilitate comprehension of the constructs being measured, the entire instrument package was provided with Visayan translations (the respondents' mother tongue).

Measuring the study's independent variable, the Functional Assessment of Chronic Illness Therapy-Spiritual Well-Being Scale (FACIT-Sp), developed by Bredle, Salsman, Debb, Arnold, and Cella (2011), is a 12-item questionnaire which uses a 5-point Likert-type scale to measure one's reported spiritual wellbeing ( 0 = Not at all; 1 = A little bit; 2 = Somewhat; 3 = Quite a bit; and $4=$ Very much). Scores on each item were summed. Interpretation and corresponding range of scores were as follows: very low (0-11), low (12-23), average (24-36), high (37-48) and very high (49-60) in spirituality.

On the other hand, measuring the study's dependent variable, Boyum's (2004) Self-Actualization scale is a 16-item questionnaire, which requires the respondent to rate on a 10-point scale, the extent to which he/she possesses the qualities of a self-actualized person as described in each item (10 being the score reflecting strong agreement to have possessed each quality). Scores in each item were summed and interpreted as: very low (16-46 points), low (47-73), average (74-103), high (104-131) and very high (132-160) in self-actualization. The highest score is 160 and the lowest score is 16 . However, there are no exact cut-off points for interpretation indicated by Boyum (2004). Grouping of scores was thus done arbitrarily in the study, bearing in mind the author's comment that the closer one is to 160 , the more self-actualized he/she is. 
Data collected were subsequently analyzed with the aid of the Statistical Package for the Social Sciences (SPSS) version 17 software. Data gathered were analyzed using percentage for profiling of respondents and Somer's $d$ for determining correlation between spirituality and self-actualization.

\section{RESULTS AND DISCUSSION}

A total of 180 older adults who met the inclusion criteria participated in the study. Table 1 presents their demographic profile.

Table 1. Respondents' Demographic Profile

$(\mathrm{N}=180)$

\begin{tabular}{|c|c|c|}
\hline Demographic Variables & Frequency & $\%$ \\
\hline \multicolumn{3}{|l|}{ Gender } \\
\hline Male & 90 & 50.0 \\
\hline Female & 90 & 50.0 \\
\hline \multicolumn{3}{|l|}{ Civil Status } \\
\hline Single & 7 & 3.90 \\
\hline Married & 104 & 57.8 \\
\hline Widow/Widower & 69 & 38.2 \\
\hline \multicolumn{3}{|l|}{ Educational Attainment } \\
\hline Elementary & 67 & 37.2 \\
\hline Secondary & 50 & 27.8 \\
\hline College & 47 & 26.1 \\
\hline Post-Graduate & 16 & 8.90 \\
\hline \multicolumn{3}{|l|}{ Status } \\
\hline Not working, with subsidy & 58 & 32.2 \\
\hline Not working & 55 & 36.8 \\
\hline With pension & 46 & 25.6 \\
\hline Working & 21 & 11.7 \\
\hline \multicolumn{3}{|l|}{ Living with } \\
\hline Children & 93 & 51.7 \\
\hline Spouse & 67 & 37.2 \\
\hline Relatives & 12 & 6.70 \\
\hline Caregiver & 8 & 4.40 \\
\hline
\end{tabular}

Note. Percentage totals may not equal 100 due to rounding. 
As shown in Table 1, there were an equal number of male and female respondents. Majority are married followed by those who are widowed. The respondents' age range from 60 to 75 years old which corresponds to the study's inclusion criteria. They mostly lived in an urban area.

It was notable that all the respondents attended school although a majority only finished elementary education. Most of them were not working but received subsidy from their children either working in the country or overseas. Other older adults had no work while others received monthly pension as a benefit from the government or private sector after retirement. Sources of income of some of the respondents included farming, fishing or being employed as drivers or laborers.

It can be deduced from the aforementioned data that although the respondents were predominantly married with both spouses still living, a majority still live with their children, tailed closely by those who were not. This implies that these married ones live together by consensual arrangement or have married children who have not owned a conjugal dwelling yet.

Majority of the respondents were receiving subsidy from their children working locally or overseas. This result implies cohesiveness among Filipino families which serve as emotional blankets for the older adults. This was reinforced by the fact that although majority of the respondents were elementary graduates only, this was not a hindrance in supporting their children who landed in jobs locally or overseas. Their effort of investing for their children's education had evidently paid off. Now, it is their children who are supporting them.

Therefore, income and financial status determined the involvement in satisfying activities or the fulfilment of the individuals' need, promoting life satisfaction among older adults (Johnson \& Krueger, 2006). The inclusion of personality in addition to health, marital status, and financial resources is needed to obtain a more accurate picture of the foundations of older adults' life satisfaction and self-actualization.

The said findings were similar to the observation of previous studies that Filipino older adults' psychological need in the hierarchy is the need to be reciprocated (Andres \& Ilada-Andres, 1996). This study led to a view that "spirituality" is important for older persons' quality of life, and especially for helping them live with the losses and limitations as well as the possibilities of their own particular situations.

Analysis of the data using Somer's $d$ was done, with spirituality being the independent variable and self-actualization the dependent variable. Table 2 shows the cross tabulation of these variables. 
Table 2. Crosstabulation for Spirituality and Self-Actualization $(\mathrm{N}=180)$

\begin{tabular}{|c|c|c|c|c|c|c|c|c|c|}
\hline \multirow{3}{*}{ Self-Actualization ${ }^{a}$} & \multicolumn{6}{|c|}{ Spirituality ${ }^{b}$} & \multirow{3}{*}{ Total } & \multirow{3}{*}{$\begin{array}{c}\text { Computed } \\
\text { values }\end{array}$} & \multirow{3}{*}{$p$-value } \\
\hline & \multicolumn{2}{|c|}{$\begin{array}{l}\text { Low } \\
(n=8)\end{array}$} & \multicolumn{2}{|c|}{$\begin{array}{c}\text { Average } \\
(n=112)\end{array}$} & \multicolumn{2}{|c|}{$\begin{array}{c}\text { High } \\
(n=60)\end{array}$} & & & \\
\hline & $f$ & $\%$ & $f$ & $\%$ & $f$ & $\%$ & & & \\
\hline Very Low & 0 & - & 2 & 1.78 & 0 & - & 2 & & \\
\hline Low & 3 & 37.50 & 8 & 7.14 & 9 & 15.0 & 20 & $\begin{array}{l}\text { Somer's } \boldsymbol{d} \\
=0.395\end{array}$ & \\
\hline Average & 2 & 25.00 & 19 & 16.96 & 11 & 18.33 & 32 & & $0.019^{*}$ \\
\hline High & 1 & 12.50 & 54 & 48.21 & 25 & 41.66 & 80 & $\begin{array}{l}T \text { value } \\
=4.20\end{array}$ & \\
\hline Very High & 2 & 25.00 & 29 & 25.89 & 15 & 25.0 & 46 & & \\
\hline
\end{tabular}

${ }^{\mathrm{a}}$ Mean $=121.12, S D=27.77 ;{ }^{\mathrm{b}}$ Mean $=33.65, S D=7.83$ ${ }^{*} p<.05$.

As shown in Table 2, many of the respondents have average ( $n=112)$ to high $(n=60)$ levels of spirituality and most also have high $(n=80)$ to very high $(n=46)$ levels of self-actualization. Furthermore, out of 180 respondents, only 8 had low levels of spirituality. This implied that majority of the respondents have achieved spiritual satisfaction.

The said results also corroborated with a survey of 203 hospitalized family practice patients from North Carolina and Pennsylvania revealed that patients often expressed strong spiritual beliefs. Most (93\%) professed a strong or somewhat strong belief in God and 94\% thought spiritual health was just as important as physical health (King \& Bushwick, 1994).

The findings were also true to the comments of the respondents that usually they will find a reason for living, feel comfort in their faith or spiritual beliefs. A certain amount of spirituality is an extremely probable consequence of a satisfied materialism.

This contention was underpinned by one of the respondents who said, "Bisan ingon ani ra amo kahimtang, kabalo ko nga naa ang Ginoo namo, kuntento nako. (I am contented for what I have now because God is with us)". Spirituality is thus important in the lives of older adults as they deal with the anxieties associated with aging, accept, grieve, cope with losses and limitation (Petrides, 2009). 
Moreover, it could be observed in Table 2 that a trend somehow existed in which those with high to very high levels of self-actualization were those older adults who have average to high levels of spirituality.

A Somer's $d$ analysis further indicated that a significant association existed between spirituality and self-actualization, $d=0.395, p=.019$. This means that one's guess for the older adult's level of self-actualization improves by $39.5 \%$ by knowing their level of spirituality. Thus, older adults who had a strong sense of spirituality are more self-actualized.

"Spirituality" according to Petrides (2009) is important in the lives of older adults as they seek to attain self-actualization. It is an active life-long process of making choices in order to reach one's potential and live life to its fullest to pursue spiritual growth. Spirituality is a predictor of self-actualization (Pausanos, 2012). They believe that whatever happens, things will be okay. Life is a conscious pursuit of spiritual growth which is one's ultimate life purpose that leads to selfactualization.

A number of studies corroborated with the said findings. According to Maslow, self-actualization is the highest level of psychological development that can be achieved after basic needs are met. It is the pinnacle of psychological health (as cited in Gleitman, Fridlund, \& Reisberg, 2004).

A meta-analysis of 34 recent studies published between 1990 and 2001 found that religiosity has a salutary relationship with psychological adjustment, being related to less psychological distress, more life satisfaction, and better self-actualization. Finally, a recent systematic review of 850 research papers on the topic concluded that "the majority of well-conducted studies found that higher levels of religious involvement are positively associated with indicators of psychological well-being (life satisfaction, happiness, positive affect, and higher morale) and with less depression, suicidal thoughts and behavior and drug/ alcohol use/abuse (Koenig \& Larson, 2001).

The satisfaction perceived from older adults' spiritual beliefs made the older person live and feel peaceful and his/her life productive. In the case of Filipino older adults, they were known for their strong religiosity, as illustrated a respondents' statement, "Ako day, ang Ginoo ra jud ang nag plano maunsa ato kinabuhi. (God has plans for me)". Dependence on the benevolence of a Transcendent Being is a deeply held value and belief amongs Filipino older adults.

Moreover, majority of the respondents are very much comfortable with their faith or spiritual beliefs. Filipino's religiosity provides a moral anchor to individuals when confronted with a personal crisis. "Nasa Diyos ang awa, nasa tao ang gawa (It is God's prerogative to show compassion. It is man's to act)" 
underscores their deep sense of the limits of human effort, even as the necessity of hard work is also recognized. Moral righteousness is often equated with being God-fearing. A person described as possessing fear of God ("takot sa Diyos") is considered trustworthy (Bulatao, 1989).

Another study revealed that people with high spiritual commitment were twice as likely to say that they were "very happy" compared to those with low spiritual commitment. This will concern only in the incidence and centrality of a person's self-defined spiritual experience. The study found out that as an older person finds his or her spiritual experience to be a central part of his or her life, the higher they will score on the self-actualization (Larsen \& Buss, 2008).

The above mentioned findings with supporting research literature strengthen and validated the implication of the findings of this study on the significant relationship between spirituality in the older adult and self-actualization, in which the older adult persons find strength in their religious beliefs and in the connectedness with the whole of creation. This, despite poverty and lack of social status, Filipino older adults were trying to be self-actualized even if not all needs in the hierarchy of Maslow where fully satisfied, and this may be due to their deep sense of spirituality. However, the resiliency of the close-knit family ties and strong spirituality of Filipinos are vital factors for the older adults to reach selfactualization. This is a unique exception to Maslow's hierarchy of needs.

\section{CONCLUSION}

The study validated one of the assumptions of Attaining Self-actualization among Older Adults. Spirituality has a bearing on self-actualization. One's sense of spirituality enhances the attainment of self-actualization among older adults. Developing a mastery of transcendental self through the spirituality aspect of a person enabled him or her to develop a sense of contentment and security.

\section{LITERATURE CITED}

Andres, T. Q. D. \& llada-Andres, P. C. B. (1996). Effective discipline through Filipino values. Quezon City, Philippines: Rex Bookstore.

Bandura, A. (1999). Social cognitive theory: An agentic perspective. Asian Journal of Social Psychology, 2(1), 21-41. doi: 10.1111/1467-839X.00024 
Berk, L.E. (2010). Development through the lifespan (5th ed.). Boston, MA: Pearson Education.

Boyum, R. (2004). Characteristics of a self-actualizing person. Retrieved fromhttp:// www.selfcounseling.com/help/personalsuccess/selfactualization.html

Bredle, J.M., Salsman, J.M., Debb, S.M., Arnold, B.J. \& Cella, D. (2011). Spiritual well-being as a component of health-related quality of life: The Functional Assessment of Chronic Illness Therapy-Spiritual Well-Being Scale (FACIT-Sp). Religions, 2, 77-94; doi:10.3390/rel2010077

Bulatao, J. (1989). Understanding the Filipino psyche. Manila, Philippines: La Salle University Press.

Cruz, G. (2004). Health transition among Filipino older people (3rd ed.). Quezon City, Philippines: Grat Book Trading Publishing.

Dehler, G.E. \& Welsh, M.A. (1994). Spirituality and organizational transformation: Implications for the new management paradigm. Journal of Managerial Psychology, 9(6), 17-26.

Ebersole, P. (2005). Gerontological nursing and healthy aging (3rd ed.). St. Louis, MO: Mosby.

Fitchett, G., \& Canada, A.L. (2012). The role of religion/spirituality in coping with cancer: Evidence, assessment, and intervention. In J. C. Holland, W. S. Breitbart, P.B. Jacobsen, M. S. Lederberg, \& M. J. Loscalzo, R. M. (Eds.). Psycho-oncology (2nd ed.). New York, NY: Oxford University Press. doi: $10.1093 / \mathrm{med} / 9780195367430.001 .0001$

Gleitman, H., Fridlund, A. J., \& Reisberg, D. (2004). Psychology (6th ed.). New York, NY: Norton \& Company.

Hodge, D.R., Bonifas, R.P. \& Chou, R.J. (2010). Spirituality and Older Adults: Ethical Guidelines to Enhance Service Provision. Advances in Social Work, 11(1), 1-16. Retrieved from https://journals.iupui.edu/index. php/ advancesinsocialwork/article/viewFile/262/404 
Janis, S. (2008). Spirituality for dummies (2nd ed.). New Jersey: Wiley.

Johnson, W., \& Krueger, R. F. (2006). How money buys happiness: Genetic and environmental processes linking finances and life satisfaction. Journal of Personality and Social Psychology, 90(4), 680-91.

King, D. E. \& Bushwick, B. (1994). Beliefs and attitudes of hospital in patients about faith healing and prayer. Journal of Family Practice, 39, 349-352.

Koenig, H. G. \& Larson, D.B. (2001). Religion and mental health: Evidence for an association. International Review of Psychiatry, 13, 67-78.

Koltko-Rivera, M. E. (2006). Rediscovering the later version of Maslow's hierarchy of needs: Self-transcendence and opportunities for theory, research, and unification. Review of General Psychology, 10(4), 302-317. doi: 10.1037/1089-2680.10.4.302.

Larsen R.J. \& Buss D.M. (2008). Personality, psychology: Domains of knowledge about human nature [International Ed.]. Boston, MA: McGraw-Hill.

Molinatti, J. P. (2012, September). The significance of spirituality in the well elderly. Paper presented at the 23rd Sigma Theta Tau International Nursing Research Congress, Brisbane, Australia.

Newport, F. (2006). Religion most important to Blacks, Women, and Older Americans. Gallup. Retrieved from http://www.gallup.com/poll/25585/ religion-most-important-blacks-women-older-americans.aspx.

Petrides, K. V. (2009). Psychometric properties of the Trait Emotional Intelligence Questionnaire (TElQue). In C. Stough, D. H. Saklofske \& J. D. A. Parker (Eds.), Assessing emotional intelligence: Theory, research, and applications (pp. 85-101). New York, NY: Springer Science \& Business Media.

Reker, G. T., \& Wong, P. T. P. (1984). Psychological and physical well-being in the elderly: The perceived well-being scale (PWB). Canadian Journal on Aging, 3(1), 23-32. 
Salovey, P. \& Mayer, J. D. (1990). Emotional intelligence. Imagination, Cognition, and Personality, 9, 185-211.

Seligman, M. (2002). "Positive emotions undo negative ones": Authentic happiness. New York, NY: Simon \& Schuster.

Taylor, R. J., Chatters, L. M., \& Jackson, J. S. (2007). Religious and spiritual involvement among older African Americans, Caribbean Blacks and non-Hispanic Whites: Findings from the National Survey of American Life. Journal of Gerontology: Social Sciences, 62, S238-S250.

Zinnbauer, B.J., Pargament, K.I. \& Scott, A.B. (1999). The emerging meanings of religiousness and spirituality: Problems and prospects. Journal of Personality, 67(6), 889-919. doi: 10.1111/1467-6494.00077 